\title{
Holger Böning, Dreißigjähriger Krieg und Öffentlichkeit
}

\author{
Claire Gantet
}

\section{OpenEdition}

Journals

Édition électronique

URL : http://journals.openedition.org/ifha/10097

DOl : $10.4000 /$ ifha. 10097

ISSN : 2198-8943

\section{Éditeur}

IFRA - Institut franco-allemand (sciences historiques et sociales)

\section{Référence électronique}

Claire Gantet, « Holger Böning, Dreißigjähriger Krieg und Öffentlichkeit », Revue de l'IFHA [En ligne], Date de recension, mis en ligne le 13 mai 2019, consulté le 24 septembre 2020. URL : http:// journals.openedition.org/ifha/10097 ; DOI : https://doi.org/10.4000/ifha.10097

Ce document a été généré automatiquement le 24 septembre 2020

(CIFHA 


\title{
Holger Böning, Dreißigjähriger Krieg und Öffentlichkeit
}

\author{
Claire Gantet
}

\section{RÉFÉRENCE}

Holger Böning, Dreißigjähriger Krieg und Öffentlichkeit. Zeitungsberichte als Rohfassung der Geschichtsschreibung, Bremen : edition lumière, 2018, 438 p., 29,80€ 
Rares sont les livres à poser de façon étayée une thèse forte et nouvelle. C'est ce à quoi procède Holger Böning avec brio dans cet ouvrage dont la portée dépasse largement la conjoncture des 400 ans du début de la guerre de Trente ans. Loin des problèmes confessionnels amplement débattus par l'historiographie, loin de la comète qui fascina tant d'historiens (voir par exemple ma recension, dans la présente Revue, d'Andreas Bähr, Der grausame Komet. 2017, http:// journals.openedition.org/ifha/10084), les contemporains s'intéressèrent avant tout aux questions politiques et militaires: la culture du secret attribuée à la vie politique de l'époque moderne est un leurre, affirme vigoureusement H. Böning (p. 10). Dès les années précédant la guerre, les contemporains furent amplement informés par le genre nouveau du journal imprimé. Bien plus, le journal s'établit d'emblée comme la lecture temporelle la plus répandue et contribua à une sécularisation de la vie sociale et politique. H. Böning prône dès lors l'usage de la catégorie de l'espace public (öffentlichkeit) dès la guerre de Trente ans, la couverture régulière des événements apparaissant comme particulièrement remarquable dans le cadre des destructions et de la désorganisation de la vie civile. Il n'entend pas imposer un nouveau récit du conflit mais revendique le recours aux journaux dans tout récit de la guerre. En conséquence, la guerre ne commença pas en 1618, mais en 1609, lorsqu'éclatèrent les premiers affrontements ouverts et que les premiers journaux devinrent réguliers puis se multiplièrent: la Relation aller Fürnemmen und gedenckwürdigen Historien (Strasbourg, 1605) fut suivie de l' Aviso, relatio oder Zeitung (Wolfenbüttel, 1609), de journaux fondés à Bâle (1610), Francfort-sur-le-Main (1615), Berlin (1617), Hambourg (1618), Halberstadt, Hildesheim, Danzig, Fribourg-en-Brisgau et Stuttgart en 1619, Francfort-sur-le-Main (deuxième journal en 1621), Vienne en 1622 puis (deuxième journal) en 1623, Königsberg et Zurich en 1623, etc., rassemblés dans l'Institut de recherche sur la presse allemande de Brême dirigé précisément par H. Böning. Or ces périodiques germanophones lancèrent un mouvement européen de fondation de journaux, à Amsterdam (1618), Anvers (1620), Paris (1631), Lisbonne (1641), Stockholm (1645) notamment. H. Böning s'attachant à mettre en valeur ce qu'ils nous disent de la guerre (en particulier dans ses premières années), il les cite longuement, sans actualiser leur langue, comme le font d'autres historiens à des fins pseudo-didactiques.

H. Böning ouvre donc son analyse par l'année 1609: d'emblée, les conflits entre l'empereur et les États de Bohême ainsi que les rois d'Espagne et de France occupèrent une presse déjà « hautement professionnelle » (p. 131), mûrie durant les décennies de journaux hebdomadaires manuscrits rassemblés notamment par les Fugger (lesdits Fuggerzeitungen) et rédigée dans des chancelleries de guerre ou des camps militaires. 
Le chapitre suivant, sur la période 1618-1621, relève le faible intérêt pour la comète et le pressentiment dès mai 1618 de l'entrée dans une guerre durable. Dès 1619, la masse d'informations est telle que des compositeurs accumulent les nouvelles sans ponctuation ni même indication de lieu et de date (p.200). Lors de la bataille de la Montagne blanche en novembre 1620, la presse omet toute mention religieuse : l'action du carmélite Domingo Ruzola est tout simplement ignorée (p. 300-310).

Au-delà des conflagrations (parfois flanquées d'intéressantes estimations de morts au combat), la presse relata de façon étonnamment fiable l'ampleur des dévastations, les souffrances des civils et les conditions de vie des mercenaires: les manques de ravitaillement, les non-versements de solde, les coûts et revenus chancelants, les rapports avec les malades, les blessés et les morts, les réactions des paysans, divers prodiges, des attaques contre les juifs. Avec un style alerte qui ne s'interdit pas des affirmations tranchées, Holger Böning en déduit que ceux qui rédigeaient ces nouvelles «étaient en aucune façon des journalistes qui comprenaient peu ou rien de ce qu'ils relataient, mais étaient si proches des groupes politiques, diplomatiques et militaires de premier plan qu'ils pouvaient juger de ce que leurs nouvelles signifiaient » (p. 378). Les journaux s'avérèrent de telles sources d'information durant la guerre que les délégués des puissances, lors des négociations de paix de Münster et d'Osnabrück, renoncent parfois à rapporter à leur maître tel événement en raison de leur couverture par les «gazettes publiques» (p. 383). Outre les 1441 missives sur les négociations, ce sont des dizaines de milliers de relations sur la guerre et les batailles qui accompagnèrent la conclusion des traités de Westphalie. Les contemporains étaient au reste conscients du pouvoir de la presse et l'employèrent aussi à des fins de propagande, pour tromper l'ennemi ou influencer le cours des négociations.

Durant la guerre, aucune bataille, aucun soulèvement paysan n'échappèrent ainsi aux journaux. S'ils ne dirent bien sûr pas la vérité, ils fonctionnèrent, plus que d'autres genres imprimés, comme une sorte de version brute de l'historiographie. H. Böning ajoute une liste détaillée des neuf journaux étudiés dans cet ouvrage.

Hormis une bourde typographique (1726 dans le titre et le haut de page au lieu de 1626, p. 353-360) et une iconographie parfois maladroite (ainsi le recours à Jacques Callot p. 350 qui, rappelons-le, n'est pas un document direct), l'ouvrage est rédigé avec un enthousiasme contagieux. Oui, les journaux, désormais disponibles sous forme numérisée pour certains d'entre eux, sont une source incontournable qui nous permettent de nuancer, voire de réviser notre vision de la guerre de Trente ans. On ne peut être que reconnaissant de cet ouvrage.

\section{INDEX}

Index chronologique : Période moderne

Thèmes : Histoire militaire 
AUTEURS

CLAIRE GANTET

Université de Fribourg (Suisse) 